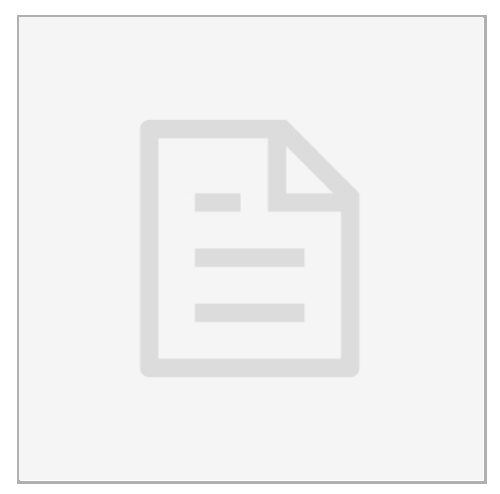

\title{
(4) Perinatal 2016 Rio Grande - Urinary Incontinence
}

\section{a PLOS One}

Yuan $\mathrm{Hsu}^{1}$, Juraci A Cesar ${ }^{1}$

${ }^{1}$ Federal University of Rio Grande

JUN 09, 2020<smiles>C1CCCCCC1</smiles>

Yuan Hsu

\section{open ठaccess}

\section{DOI:}

dx.doi.org/10.17504/protocol s.io.bfxz.jpp6

\section{External link:}

https://doi.org/10.1371/journa l. pone. 0234338

Document Citation: Yuan Hsu, Juraci A Cesar 2020. Perinatal 2016 Rio Grande Urinary Incontinence. protocols.io

https://dx.doi.org/10.17504/p rotocols. io. bfxz.jpp6

\section{MANUSCRIPT CITATION:}

Ting HY, Cesar JA (2020) Urinary incontinence among pregnant women in Southern Brazil: A population-based cross-sectional survey. PLoS ONE 15(6): e0234338. doi: $\underline{10.1371 / \text { journal.pone. } 023433}$ $\underline{8}$

License: This is an open access document distributed under the terms of the Creative Commons Attribution License, which permits unrestricted use, distribution, and reproduction in any medium, provided the original author and source are credited

Created: May 04, 2020

Last Modified: Jun 09, 2020 
DOCUMENT integer ID:

36569

Dataset

Perinatal 2016

NAME

\section{Perinatal_2016_Rio Grande.dta}

